\title{
CCAAT/Enhancer Binding Protein-delta (C/EBP-delta) regulates cell growth, migration and differentiation
}

\author{
Xueyan Yu, Junling Si, Yingjie Zhang, James W DeWille*
}

\begin{abstract}
Background: CCAAT/enhancer binding protein-delta (C/EBP-delta) is a member of the highly conserved C/EBP family of basic region leucine zipper transcription factors. C/EBP family members regulate cell growth and differentiation and "loss of function" alterations in C/EBPs have been reported in a variety of human cancers. C/ EBP-delta gene expression is upregulated by $G_{0}$ growth arrest, IL- 6 family cytokines and endotoxin treatments. C/ EBP-delta exhibits properties of a tumor suppressor gene, including reduced expression and promoter methylationinduced silencing in transformed cell lines and primary tumors. In addition, C/EBP-delta gene expression is repressed by c-Myc, an oncogene that is over-expressed in a wide range of human cancers. "ChIP-chip" studies demonstrated that C/EBP-delta functions as a transcriptional activator of target genes that function in intracellular signal transduction, transcription, DNA binding/repair, cell cycle control, cell adhesion, and apoptosis. Despite progress in determining the biochemical functions of C/EBP-delta, the specific cellular defects that are induced by C/EBP-delta "loss of function" alterations are poorly understood. This study investigated the impact of C/EBP-delta "loss of function" alterations on growth arrest, migration/invasion and differentiation in nontransformed mouse mammary epithelial cells (MECs) and primary mouse embryo fibroblasts (MEFs).
\end{abstract}

Results: C/EBP-delta siRNA transfected MECs exhibited $~ 90 \%$ reduction in C/EBP-delta mRNA and protein levels. C/ EBP-delta siRNA treatment resulted in defective growth arrest as demonstrated by persistently elevated BrdU labeling, ${ }^{3} \mathrm{H}$-thymidine incorporation and cyclin D1 levels in response to growth arrest treatments. C/EBP-delta siRNA treatment also resulted in increased migration/invasion and defective differentiation. C/EBP-delta knockout MEFs exhibited defective growth arrest and increased proliferation/migration. Re-introduction of C/EBP-delta expression restored the growth arrest response of C/EBP-delta knockout MEFs. Finally, deletion of the C/EBP-delta DNA binding domain or the C/EBP-delta bZIP domain resulted in the loss of C/EBP-delta growth inhibition in clonogenic assays.

Conclusions: This study demonstrates that C/EBP-delta functions in the regulation of critical cell fate determining programs such as growth arrest, migration, and differentiation. These results support the tumor suppressor function of C/EBP-delta and identify potential mechanisms in which "loss of function" alterations in C/EBP-delta could promote cell transformation and tumorigenesis.

\section{Background}

CCAAT/enhancer binding proteins (C/EBPs) are a highly conserved family of basic region leucine zipper (bZip) transcription factors [1]. The C/EBP family includes six family members: $\mathrm{C} / \mathrm{EBP} \alpha, \mathrm{C} / \mathrm{EBP} \beta, \mathrm{C} / \mathrm{EBP} \gamma$,

\footnotetext{
* Correspondence: dewille.1@osu.edu

Department of Veterinary Biosciences, Ohio State University College of Veterinary Medicine and OSU Comprehensive Cancer Center, 1925 Coffey Road, Columbus Ohio, 43210, USA
}

(c) 2010 Yu et al; licensee BioMed Central Ltd. This is an Open Access article distributed under the terms of the Creative Commons Attribution License (<url>http://creativecommons.org/licenses/by/2.0</url>), which permits unrestricted use, distribution, and reproduction in any medium, provided the original work is properly cited.
C/EBP $\delta, C / E B P \varepsilon$, and C/EBP $\zeta[1,2]$. C/EBP proteins exhibit significant amino acid homology $(>90 \%)$ in the bZip (C-terminal) domain, however, the N-terminal regions of C/EBPs are quite divergent exhibiting $<20 \%$ sequence homology [1]. C/EBPs influence cell fate by forming homo- or heterodimers with other C/EBP family members as well as other bZip-containing proteins such as Fos, Jun and cyclic AMP response element binding protein (CREB) [1-3]. C/EBPs also interact with 
cell cycle regulators such as Retinoblastoma protein $(\mathrm{Rb}), \mathrm{E} 2 \mathrm{~F}$, cyclin dependent kinase4 (CDK4) and p21 via the C/EBP $\mathrm{N}$ terminal region [1-3]. C/EBP family members, particularly $\mathrm{C} / \mathrm{EBP} \alpha$ and $\mathrm{C} / \mathrm{EBP} \delta$, exhibit cell type specific anti-proliferative activities and, as a result, have been termed "molecular stop signs" $[2,4]$.

$\mathrm{C} / \mathrm{EBP} \delta$ gene expression is highly induced in a wide range of cell types by growth arrest treatments [2]. C/ $\mathrm{EBP} \delta$ is induced in primary human mammary epithelial cells and human and mouse non-transformed mammary epithelial cell lines in response to growth arrest treatments (serum and growth factor withdrawal, contact inhibition) and IL-6 family cytokine treatment [5-8]. C/ EBP $\delta$ is also induced in human prostate cancer derived cells (LnCAP) and in KCL22 and K562 chronic myelogenous leukemia $(\mathrm{CML})$ cell lines in response to growth arrest and IL-6 family treatments $[9,10]$. The induction of $\mathrm{C} / \mathrm{EBP} \delta$ expression in response to growth arrest treatments has functional consequences as ectopic C/EBP $\delta$ expression induces growth arrest in mammary epithelial, prostate, CML and AML derived cell lines [6,9-11]. In addition, C/EBP $\delta$ knockout female mice exhibit increased mammary epithelial cell proliferation and ductal hyperplasia, demonstrating that reduced C/EBP $\delta$ expression results in mammary epithelial cell growth abnormalities in vivo [12].

$\mathrm{C} / \mathrm{EBP} \delta$ "loss of function" alterations have been demonstrated in a number of human cancers. We reported that $\mathrm{C} / \mathrm{EBP} \delta$ expression is reduced in $32 \%$ (18/ 57) of primary human breast tumors, a finding consistent with Serial Analysis of gene Expression (SAGE) results from Polyak and coworkers [13-15]. The association between reduced C/EBP $\delta$ expression and mammary tumorigenesis has also been demonstrated in mammary tumor prone MMTV/c-neu transgenic mice and rodent carcinogen-induced mammary tumors, indicating that reduced $\mathrm{C} / \mathrm{EBP} \delta$ expression is relatively common in mammary epithelial cell tumors regardless of species or transforming event $[16,17]$. Mechanistic studies indicate that hypermethylation and site-specific methylation within the C/EBP $\delta$ proximal promoter is associated with reduced C/EBP $\delta$ gene expression in the human SUM$52 \mathrm{PE}$ breast cancer cell line and in primary human breast tumors [13]. Silencing of gene expression by epigenetic promoter hypermethylation has been previously reported for a number of tumor suppressor genes including Rb, p16, p21, BRCA1 and VHL [18]. These results demonstrate that $\mathrm{C} / \mathrm{EBP} \delta$ shares cancer related mechanisms of gene silencing with established tumor suppressor genes.

C/EBPs function as transcriptional regulators in the differentiation of a variety of cell types, including adipocytes, mammary epithelial cells, myeloid cells, keratinocytes and hepatocytes $[1,19]$. Sequential expression of C/
EBP $\delta, \beta$ and $\alpha$ has been extensively documented in adipocyte differentiation [20]. C/EBP $\alpha, C / E B P \beta$ knockout mice and $C / E B P \beta / \delta$ double knockout mice exhibit reduced in vitro adipocyte differentiation and reduced in vivo lipid accumulation in adipose tissue [21,22]. C/ $\mathrm{EBP} \delta$ is also important in differentiation of cells in the myeloid lineage as ectopic C/EBP $\delta$ expression induces growth arrest and differentiation in chronic myelogenous leukemia cell lines [10]. In contrast, inhibiting C/ EBP $\delta$ expression suppresses cytokine-induced granulocytic differentiation of human myeloid leukemia cells [23].

The overall goal of this study was to investigate the influence of $\mathrm{C} / \mathrm{EBP} \delta$ on growth arrest, migration, invasion and differentiation. Alterations in these fundamental cell programs are common in cancer cells [24]. The results demonstrated that reducing $\mathrm{C} / \mathrm{EBP} \delta$ expression impairs mammary epithelial cell (MEC) growth arrest, increases MEC migration/invasion and reduces MEC differentiation. In addition, C/EBP $\delta$ knockout MEFs also exhibited defective growth arrest and increased migration compared to C/EBP $\delta$ wild type MEFs. These results provide mechanistic insights into the role of C/EBP $\delta$ "loss of function" alterations" in cell transformation and tumorigenesis.

\section{Results}

Reducing C/EBP $\delta$ expression by C/EBP $\delta$ siRNA treatment results in defective $\mathrm{HC} 11$ mammary epithelial cell growth arrest

Previous reports from our lab and others have demonstrated that $\mathrm{C} / \mathrm{EBP} \delta$ gene transcription is highly induced during $G_{0}$ growth arrest and $C / E B P \delta$ gene expression is reduced in breast cancer cell lines and primary breast tumors $[7,8,13,15]$. To investigate the functional role of C/EBP $\delta$ in mammary epithelial cell $G_{0}$ growth arrest we developed stably transfected C/EBP $\delta$ siRNA expressing and vector control $\mathrm{HC} 11$ cell lines. Stable C/EBP $\delta$ siRNA expressing HC11 cells exhibited $~ 90 \%$ reduction in C/EBP $\delta$ mRNA and protein levels compared to HC11 parental and vector controls (Figure 1AB). The influence of $\mathrm{C} / \mathrm{EBP} \delta$ expression $\mathrm{HC} 11$ cell growth was investigated by culturing $\mathrm{HC} 11$ cell lines under exponentially growing or growth arrest conditions. Cell growth (cell proliferation) status was assessed using bromodeoxyuridine (BrdU) in situ labeling as an indicator of S phase DNA synthesis. The number of BrdU positive nuclei detected in all $3 \mathrm{HC} 11$ cell lines cultured under exponentially growing cell culture conditions was approximately similar, suggesting that $\mathrm{C} / \mathrm{EBP} \delta$ does not play a major role under conditions in which cells are actively proliferating (Figure 1C, left column). The number of BrdU positive nuclei was dramatically reduced, however, when parental and vector control $\mathrm{HC} 11$ cells were cultured under growth arrest conditions for 48 hours (Figure 1C, right 

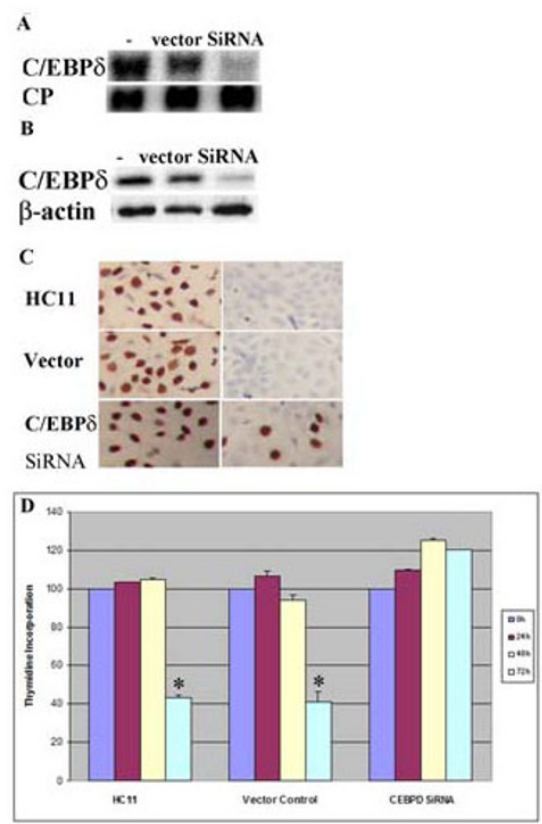

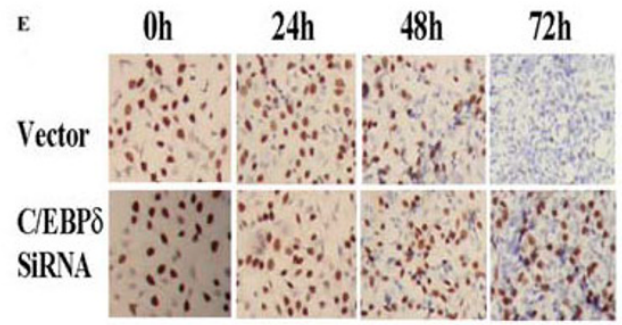

F HC11 vector SiRNA 024487202448720244872
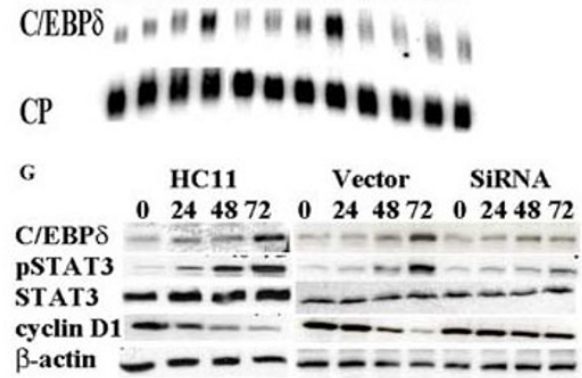

Figure 1 Reducing C/EBP $\delta$ expression by C/EBPס siRNA treatment results in defective HC11 mammary epithelial cell growth arrest. (A) C/EBP $\delta$ mRNA levels were assessed in parental (nontransfected) HC11 cells ("-"), empty vector (pSilencer ${ }^{\mathrm{TM}} 2.1$ ) transfected HC11 controls ("vector") and C/EBP $\delta$ siRNA transfected ("siRNA") HC11 cells growth arrested by serum and growth factor withdrawal. Northern blots were probed with ${ }^{32}$-labelled C/EBP $\delta$ and cyclophilin (CP, loading control) CDNA probes. (B) C/EBP $\delta$ protein levels were assessed in parental (nontransfected) HC11 cells (-), empty vector transfected HC11 controls (vector) and C/EBP $\delta$ siRNA transfected (siRNA) HC11 cells growth arrested by serum and growth factor withdrawal. Western blots were probed with primary antibodies against C/EBP $\delta$ and $\beta$-actin (loading control). (C) Serum and growth factor withdrawal induced growth arrest assessed by BrdU labeling (brown). HC11 cells were cultured under exponentially growing (first panel) and $48 \mathrm{hr}$ growth arrested (second panel) conditions. Cells were counterstained with hematoxylin (blue). (D) Contact inhibition (growth arrest) assessed by $\left.{ }^{3} \mathrm{H}\right]$-thymidine incorporation. HC11 nontransfected control, HC11 vector control and HC11 C/EBP $\delta$ siRNA transfected cells were grown to $\sim 80 \%$ confluence $\left(0 \mathrm{hr}\right.$ ) in complete growth media (CGM) and then maintained in CGM. $\left[{ }^{3} \mathrm{H}\right]$-thymidine incorporation (cpm) was assessed at 0, 2448 and 72 hours. (E) Contact inhibition (growth arrest) assessed by BrdU incorporation (brown). Cells were treated as described in " $\mathrm{D}$ " above. BrdU incorporation was assessed at the designated time points. (F) Contact inhibition (growth arrest) induction of C/EBP $\delta$ mRNA levels. Total RNA was isolated at the designated time points and Northern blots were probed with ${ }^{32} \mathrm{P}$-labelled C/ EBP $\delta$ and cyclophilin (CP, loading control) CDNA probes. (G) Whole cell proteins were isolated at designated time points and Western blots were probed with primary antibodies against STAT3, PSTAT3, C/EBP $\delta$, cyclin D1 and $\beta$-actin (loading control). ${ }^{*}=$ significant different from C/EBP $\delta$ siRNA treated group at 72 hours at $p<0.05$.

panel). In contrast, the number of BrdU positive nuclei was sustained at relatively elevated levels in the C/EBP $\delta$ siRNA expressing HC11 cells after cultured under growth arrest conditions for 48 hours (Figure. 1C, right panel). These results indicate that serum and growth factor withdrawal activates the growth arrest response in C/EBP $\delta$ expressing $\mathrm{HC} 11$ cells, but $\mathrm{HC} 11$ cells with reduced $\mathrm{C} / \mathrm{EBP} \delta$ expression retain the capacity to proliferate in serum and growth factor deficient media.

We next investigated the effect of reduced C/EBP $\delta$ expression on contact mediated growth arrest. To assess contact mediated growth arrest near $(\sim 80 \%)$ confluent HC11 cell lines were cultured in media containing serum and growth factors (complete growth media, CGM) for up to 72 hours. $\left[{ }^{3} \mathrm{H}\right]$ thymidine incorporation and BrdU labeling were assessed as indicators of proliferation post confluence. $\mathrm{HC} 11$ parental and vector control cells exhibited a significant decline in $\left[{ }^{3} \mathrm{H}\right]$ thymidine incorporation after 72 hours (Figure 1D). In contrast, $\left[{ }^{3} \mathrm{H}\right]$ thymidine incorporation remained elevated after 72 hours post confluence in C/EBP $\delta$ siRNA transfected HC11 cells (Figure 1D). Consistent with the $\left[{ }^{3} \mathrm{H}\right]$ thymidine incorporation data, the BrdU in situ labeling results also demonstrated that C/EBP $\delta$ siRNA transfected HC11 cells exhibit impaired contact inhibition (increased BrdU positive nuclei) at 72 hours compared to vector transfected controls (Figure 1E). These results demonstrate that contact mediated growth arrest is defective in C/EBP $\delta$ siRNA transfected $\mathrm{HC} 11$ cells.

We next assessed the association between contact mediated growth arrest and cellular markers of proliferation and growth arrest. Consistent with previous reports from our laboratory, C/EBP $\delta$ mRNA levels increase as parental and vector control HC11 cells progress from sub confluence $(0 \mathrm{hr})$ to full confluence $(72$ hrs) (Figure 1F) $[5,25]$. In contrast, C/EBP $\delta$ mRNA 
levels are not significantly induced in C/EBP $\delta$ siRNA expressing $\mathrm{HC} 11$ cells cultured under the same conditions of confluence (Figure 1F). Previous reports from our laboratory and others have demonstrated that activated (phosphorylated) STAT3 (pSTAT3) is the principal transcriptional activator of $\mathrm{C} / \mathrm{EBP} \delta$ gene expression in mouse and human cells in response to growth arrest conditions [25-28]. Reports from our lab and others have also demonstrated that PSTAT3 levels increase in growth arrested, nontransformed cells, but alterations in pSTAT3 levels and pSTAT3 mediated C/EBP $\delta$ gene expression are demonstrable in cancer cell lines $[8,9,13,25,29-32]$. Western blot analysis demonstrated that as parental and vector control $\mathrm{HC} 11$ cell lines approach contact mediated growth inhibition (48-72 hours), pSTAT3 and C/EBP $\delta$ protein levels increase and the levels of Cyclin D1, a marker of cell cycle proliferation, decline (Figure 1G). In contrast, pSTAT3 and C/ $\mathrm{EBP} \delta$ protein levels remain relatively low and Cyclin D1 levels remain elevated in $\mathrm{C} / \mathrm{EBP} \delta$ siRNA treated $\mathrm{HC} 11$ cells (Figure 1G). Taken together, these results demonstrate that reducing C/EBP $\delta$ expression by siRNA treatment results in defective growth arrest in nontransformed HC11 mammary epithelial cells.

\section{Reducing C/EBP $\delta$ expression increases $\mathrm{HC} 11$ cell migration and invasion}

We previously demonstrated by "ChIP-chip" assay that $\mathrm{C} / \mathrm{EBP} \delta$ activates target genes that function cell adhesion, including integrin $\beta 8$ (ITGB8), protocadherin 9 (PCDH9) and glycoprotein V (GP5) [33]. We hypothesized that in addition to defective growth control, "loss of function" alteration in C/EBP $\delta$ may also influence cell migration. HC11 cell migration was assessed using the in vitro "scratch" assay, an assay that assesses the capacity of cells to migrate into an open area created by "scratching" a confluent cell monolayer [34-36]. The "scratch' assay was performed on confluent monolayers of HC11 cells cultured in complete growth media and migration into the open area assessed at 0,24 and 48 hours post-scratch. The results demonstrated that $\mathrm{C} /$ EBP $\delta$ siRNA transfected HC11 cells exhibited enhanced migration into the open area of the cell monolayer compared to parental or vector control cells (Figure 2A). To determine the influence of exogenous growth factors on cell migration the scratch assay was performed with cells cultured at confluence in media lacking serum and growth factors (Growth arrest media, GAM). Although overall migration was significantly reduced in all cells cultured in GAM, the number of cells migrating into the open area was increased in the C/EBP $\delta$ siRNA transfected HC11 cells compared to the parental and vector control groups (Figure 2B). These results demonstrate that reducing $\mathrm{C} / \mathrm{EBP} \delta$ expression is associated with

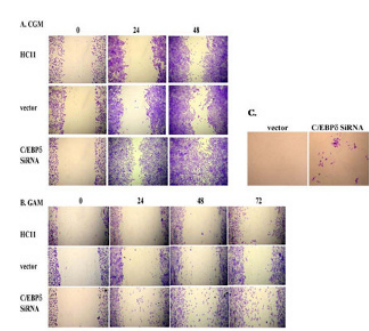

Figure 2 Reducing C/EBP $\delta$ expression increases $\mathrm{HC} 11$ cell migration and invasion. (A) HC11 nontransfected cells, HC11 stably transfected vector ( $p$ Silencer ${ }^{\text {TM }} 2.1$ neo) control ("vector") cells and $\mathrm{HC} 11 \mathrm{C} / \mathrm{EBP} \delta$ siRNA treated cells were grown to confluence in CGM. A $200 \mu$ l pipet tip was used to produce an open area or "scratch" in the confluent monolayers and migration into the open area assessed at $0 \mathrm{~h}, 24 \mathrm{~h}$ and $48 \mathrm{~h}$ by crystal violet staining. (B) $\mathrm{HC} 11$ cell lines were grown to confluence in CGM and then switched to growth arrest media (GAM, 0.1\% FBS) for 24 hours prior to the creation of the open area in the cell monolayers. Migration into the open area in the GAM cultured cells was assessed as described in "A" above. (C) HC11 vector control and C/EBP $\delta$ siRNA treated cells $\left(1 \times 10^{6}\right)$ were suspended in serum-free media and cultured on the inner (top) chamber of the insert; serum containing media was placed in the outer (lower) chamber of the insert (Chemicon Cell Invasion Assay Kit). Plates were incubated for up to 6 days at $37^{\circ} \mathrm{C}$. Migration of cells to the lower surface of the membrane was assessed by staining with crystal violet and photographed. Results presented are representative of 3 independent experiments with duplicates.

increased cell migration, a property of transformed cells that is linked to metastasis [35].

To determine if the increased cell migration capability exhibited by $\mathrm{C} / \mathrm{EBP} \delta$ siRNA treated $\mathrm{HC} 11$ cells also increased cell invasion we performed cell invasion assays. $\mathrm{C} / \mathrm{EBP} \delta$ siRNA expressing and vector control HC11 cells were cultured in GAM on extracellular matrix (ECM) coated inserts and invasion was assessed by crystal violet staining of cells traversing to the reverse side of the insert. Although nontransformed $\mathrm{HC} 11$ cell line is minimally invasive in this assay, the results demonstrated that siRNA mediated reduction of C/EBP expression increased $\mathrm{HC} 11$ cell invasion through the $\mathrm{ECM}$, indicating that "loss of function" alterations in $\mathrm{C} /$ EBP $\delta$ are associated with enhanced cell invasion (Figure $2 \mathrm{C})$.

\section{Reducing C/EBPS expression inhibits HC11 mammary epithelial cell differentiation}

Early reports associated C/EBP $\delta$ expression with adipocyte differentiation and subsequent studies established that $\mathrm{C} / \mathrm{EBP} \delta$ plays a key regulatory role in adipocyte and granulocyte differentiation $[10,37]$. Since C/EBP $\delta$ is involved in the differentiation of cell types of various lineages we hypothesized that loss of C/EBP $\delta$ expression would alter mammary epithelial cell differentiation. 
Confluent HC11 cells were treated with a media containing lactogenic hormones and the influence of $\mathrm{C} /$ EBP $\delta$ expression on $\mathrm{HC} 11$ cell differentiation was assessed by Northern blot analysis of $\beta$-casein mRNA, a marker of mammary epithelial cell differentiation [17]. The results demonstrated that $\beta$-casein mRNA levels increased in the HC11 parental and vector control cell lines in response to lactogenic hormone treatment ("+" columns) compared to control cell lines cultured in the absence of lactogenic hormones ("-" columns)(Figure 3). In contrast, lactogenic hormone induction of $\beta$-casein mRNA levels in C/EBP $\delta$ siRNA transfected HC11 cells was minimal, $\sim 20 \%$ of that observed in the C/EBP $\delta$ expressing control cell lines (Figure 3). These results demonstrate that reducing endogenous $\mathrm{C} / \mathrm{EBP} \delta$ levels is associated with defective HC11 mammary epithelial cell differentiation.

\section{C/EBPS knockout (C/EBP -/-) mouse embryo fibroblasts (MEFs) exhibit defective growth arrest and increased migration}

Primary mouse embryo fibroblasts (MEFs) have been extensively used as a model system to investigate the role of specific gene deletions in cell biology [38]. We hypothesized that C/EBP $\delta$-/- MEFs could serve as a useful model to investigate the tumor suppressor functions of C/EBP $\delta$. C/EBP +/+ and C/EBP -/- MEFs were grown to near confluence $(0 \mathrm{hr})$, switched from MCGM to GAM, and growth arrest induction of C/EBP $\delta$ protein levels assessed. C/EBP $\delta+/+$ MEFs exhibited marked induction of C/EBP $\delta$ protein levels 24 and 48 hours after exposure to GAM (Figure 4A). In contrast, C/EBP $\delta$ protein levels were undetectable in C/EBP $\delta$-/- MEFs cultured in GAM, confirming the total abrogation of C/ EBP $\delta$ expression in C/EBP $\delta$-/- MEFs (Figure 4A). Next, we cultured near confluent ( $\sim 80 \%$ confluent) C/EBP $\delta$ $+/+$ and C/EBP $\delta$-/- MEFs in media deficient in serum and growth factors (growth arrest media, GAM) and assessed the growth arrest response using $\left[{ }^{3} \mathrm{H}\right]$ thymidine incorporation and BrdU labeling as $\mathrm{S}$ phase (proliferation) indicators. The results demonstrated that $\mathrm{C} /$ EBP $\delta+/+$ MEFs exhibited a rapid, time dependent (within $24 \mathrm{hrs}$ ) decline in $\left[{ }^{3} \mathrm{H}\right]$ thymidine incorporation following exposure to GAM (Figure 4B). This decline in $\left[{ }^{3} \mathrm{H}\right]$ thymidine incorporation persisted in the C/EBP $\delta$ $+/+$ MEFs at the $48 \mathrm{hr}$ time point (Figure 4B). In contrast, $\left[{ }^{3} \mathrm{H}\right]$ thymidine incorporation remained elevated in the C/EBP $\delta$-/- MEFs after prolonged (48 hours) of culture in GAM (Figure 4B). Similarly, BrdU labeling declined in C/EBP $\delta+/+$ MEFs after 24 and 48 hours of culture in GAM (Figure 4C). BrdU labeling remained elevated in C/EBP $\delta$-/- MEFs after 24 and 48 hours of culture in GAM (Figure 4C). To further investigate the role of $\mathrm{C} / \mathrm{EBP} \delta$ in contact-mediated growth arrest $\mathrm{C} /$ EBP $\delta$-/ - MEFs were transfected with an empty expression plasmid (pcDNA3) or a C/EBP $\delta$ expression plasmid and cultured in MEF Complete Growth Media (MCGM). C/EBP $\delta$-/- MEFs receiving the C/EBP $\delta$ expression plasmid exhibited decreased $\left[{ }^{3} \mathrm{H}\right]$ thymidine incorporation, consistent with growth inhibition (Figure $4 \mathrm{D})$. In contrast, $\left[{ }^{3} \mathrm{H}\right]$ thymidine incorporation continued to increase in C/EBP $\delta$-/ - MEFs transfected with the empty pcDNA3 control vector (Figure 4D). These results demonstrate that $\mathrm{C} / \mathrm{EBP} \delta$ plays a key role in activating growth arrest in MEFs. We next investigated the influence of C/EBP $\delta$ on MEF migration using the in vitro scratch assay. The results demonstrated that a uniform open area was created on the C/EBP $\delta-/-$ and C/ $\mathrm{EBP} \delta-/$ - MEF cell monolayers at $\mathrm{t}=0$ (Figure 4E). After 24 hours, however, the C/EBP $\delta$-/- MEFs

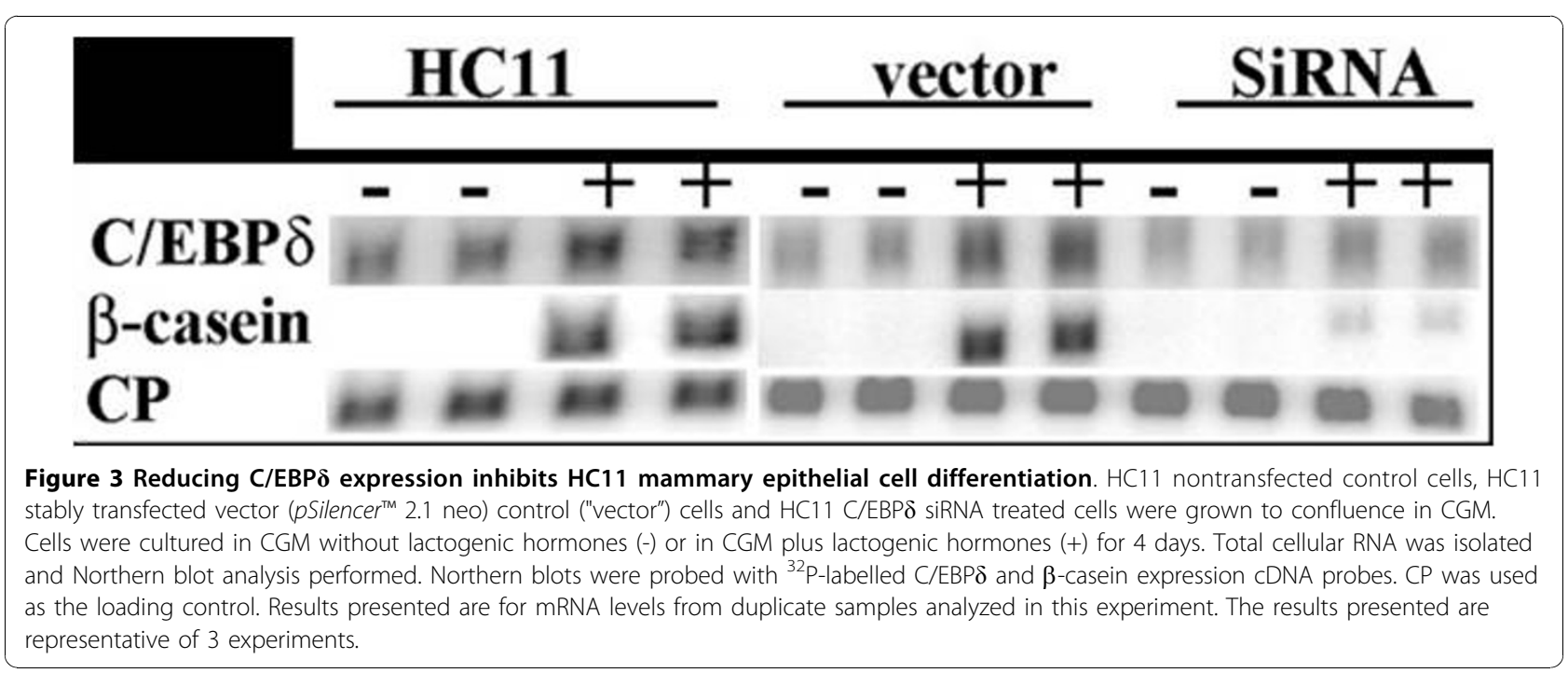



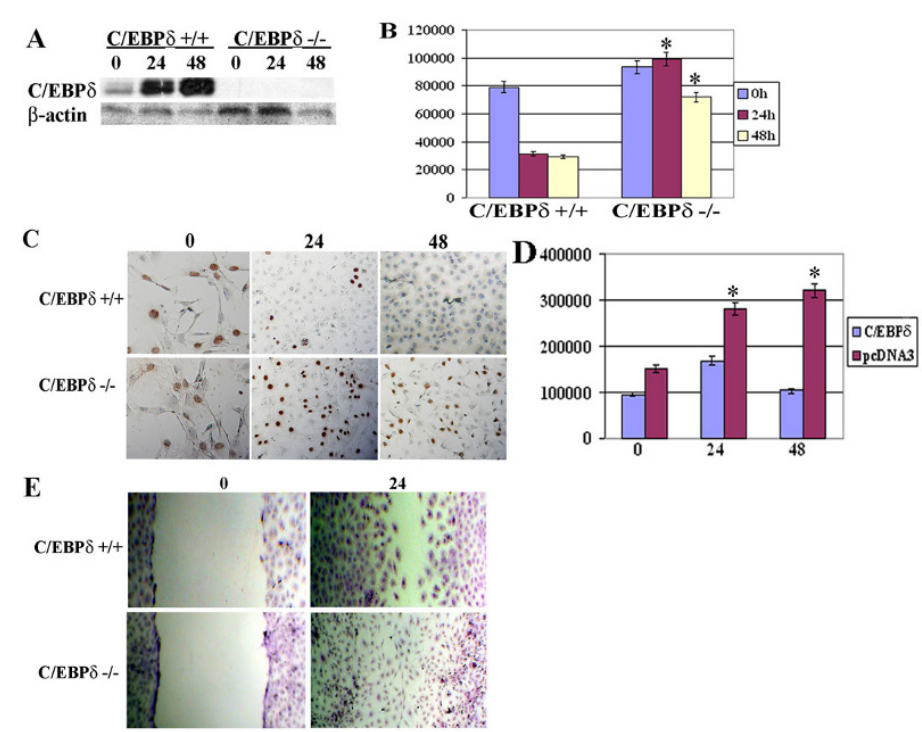

Figure 4 C/EBP $\delta$ knockout (C/EBP -/-) mouse embryo fibroblasts (MEFs) exhibit defective growth arrest and increased migration. (A) C/ EBP $\delta$ protein levels in C/EBP $\delta+/+$ and C/EBP $\delta$-/- MEFs. C/EBP $\delta+/+$ and C/EBP $\delta$-/- MEFs were cultured in MCGM to $~ 80 \%$ confluence and then switched to GAM. Whole cell lysates were isolated and western blots performed at 0 (near confluence), 24 and 48 hrs. Western blots were probed with anti- C/EBP $\delta$ and $\beta$-actin antibodies. (B) $\left[{ }^{3} \mathrm{H}\right]$-thymidine incorporation. C/EBP $\delta+/+$ and $\mathrm{C} / \mathrm{EBP} \delta-/-\mathrm{MEF}$ were treated as described in "A" above. [ ${ }^{3} \mathrm{H}$-thymidine incorporation assessed at 0,24 and 48 hrs. ${ }^{*}=$ significantly different from C/EBP $\delta+/+$ treatment group at 24 and 48 hours at $p<0.05$. (C) BrdU labeling. C/EBP $\delta+/+$ and C/EBP $\delta-/-$ MEFs were treated as described in " $A$ " and BrdU labeling detected by in situ

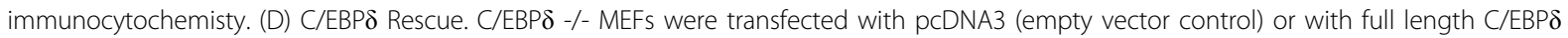
cloned into pcDNA3. Confluent cells were cultured in MCGM and [ $\left.{ }^{3} \mathrm{H}\right]$-thymidine incorporation assessed at 0,24 and 48 hrs post-confluence. The values presented are mean \pm S.E.M from three independent experiments. ${ }^{*}=$ significantly different from MEFs transfected with C/EBP $\delta$ expression vector at 24 and 48 hours at $p<0.05$. Migration assay. C/EBP $\delta+/+$ and C/EBP $\delta$ - /- MEF confluent monolayers cultured in MCGM were "scratched" with a $200 \mu \mathrm{L}$ pipet tip as described in the Methods section. Migration of cells into the open area was assessed at 0 and 24 hrs by crystal violet staining.

demonstrated a markedly elevated migration into the open area compared to C/EBP $\delta+/+$ MEFs (Figure 4E). These results are consistent with the results presented in Figure 2 and further demonstrate that "loss of function" alterations in C/EBP $\delta$ enhance cell migration.

\section{C/EBP $\delta$ DNA binding and bZIP domains function in the suppression of $\mathrm{HC} 11$ cell colony growth}

$\mathrm{C} / \mathrm{EBPs}$ are organized in a domain structure composed of an $\mathrm{N}$ terminal transactivation domain, regulatory domain and highly conserved $\mathrm{C}$-terminal basic region (BR) and leucine zipper (bZIP) domains [2]. CEBPs function primarily as DNA binding transcriptional activators $[1,2]$. To determine if the $\mathrm{C} / \mathrm{EBP} \delta$ transcriptional activation function plays a role in colony growth $\mathrm{HC} 11$ cells were transfected with $\mathrm{C} / \mathrm{EBP} \delta$ full length and $\mathrm{C} /$ $\mathrm{EBP} \delta \mathrm{bZIP}$ and $\mathrm{C} / \mathrm{EBP} \delta \mathrm{BR}+\mathrm{bZIP}$ deletion constructs and colony growth (clonogenic) assays performed. The results demonstrated that the $\mathrm{C} / \mathrm{EBP} \delta$ full length construct suppressed $\mathrm{HC} 11$ cell colony growth compared to the transcriptional activation defective $\mathrm{C} / \mathrm{EBP} \delta$ bZIP and $\mathrm{C} / \mathrm{EBP} \delta \mathrm{BR}+\mathrm{bZIP}$ deletion constructs (Figure 5). These findings demonstrate that the $\mathrm{C} / \mathrm{EBP} \delta$ domains that mediate transcriptional activation (i.e., BR and bZIP) play a major role in $\mathrm{C} / \mathrm{EBP} \delta$ mediated suppression of HC11 cell colony growth.

\section{Discussion}

These findings provide mechanistic insights into the role of $\mathrm{C} / \mathrm{EBP} \delta$ as a tumor suppressor gene and support experimental and clinical reports that have linked "loss of function" alterations in C/EBP $\delta$ with aberrant cell growth and tumorigenesis [6,8-11,13-15,39]. Early reports demonstrated that $\mathrm{C} / \mathrm{EBP} \delta$ functioned as a transcriptional activator in growth arrest and differentiation of pre-adipocyte and acute phase responding cells $[37,40]$. The results from this study extend these results to nontransformed mammary epithelial cells and primary embryo-derived fibroblasts, demonstrating that $\mathrm{C} /$ $\mathrm{EBP} \delta$ regulates cell fate determining programs in a broad range of cell types. Recent studies indicate that $\mathrm{C} /$ EBP $\delta$ gene expression is induced in hormone responsive breast and prostate cancer cells, but $\mathrm{C} / \mathrm{EBP} \delta$ induction and growth arrest is lost in more advanced, hormone unresponsive breast and prostate cancer cells [39]. In addition to breast and prostate, the association between $\mathrm{C} / \mathrm{EBP} \delta$, growth control and differentiation extends to myeloid lineage cells. $\mathrm{C} / \mathrm{EBP} \delta$ expression is silenced by 


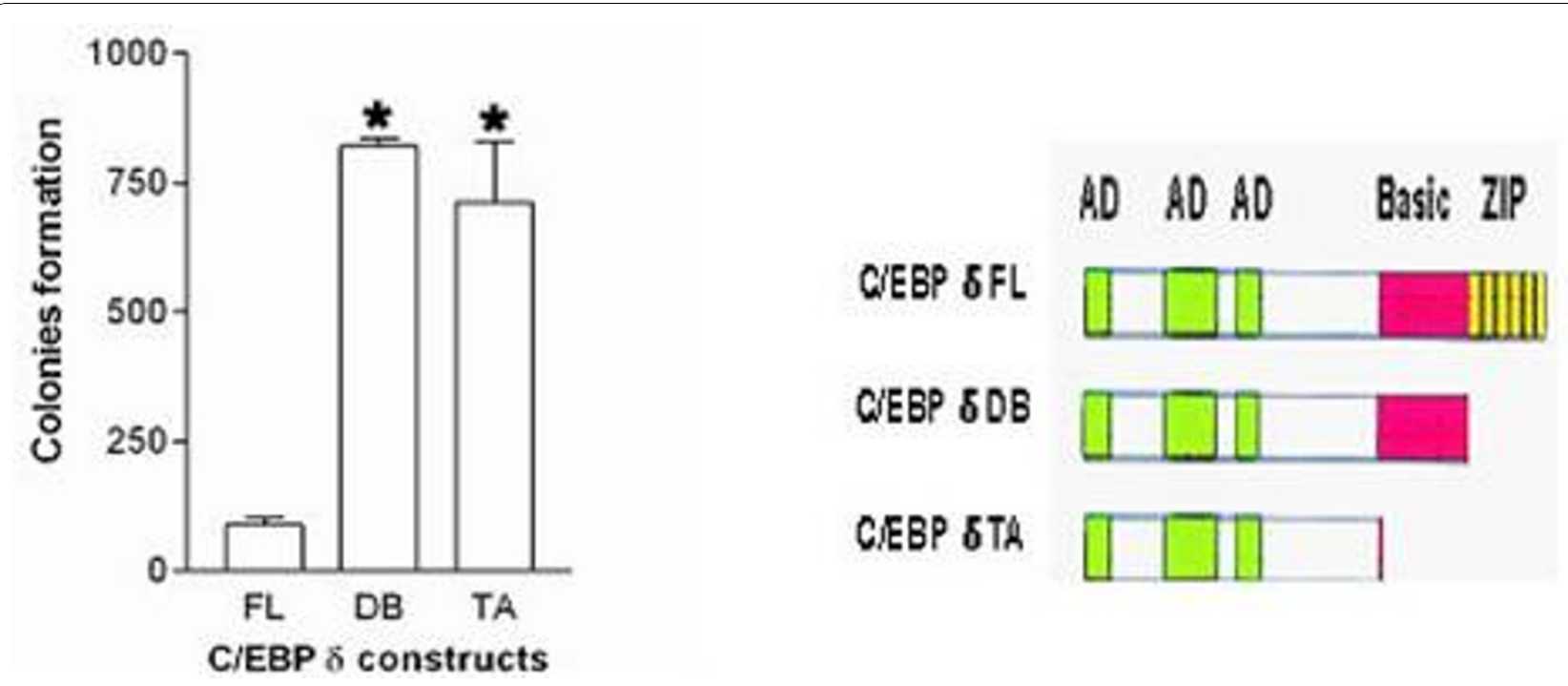

Figure 5 C/EBP $\delta$ transcriptional activator function is required for suppression of HC11 mammary epithelial cell colony growth. HC11 cells were transfected with expression constructs encoding C/EBP $\delta$ CDNA full length (FL), C/EBP $\delta$ bZIP domain deleted (DB) or C/EBP $\delta$ bZIP + DNA binding domain deleted (TA) constructs. HC11 cells transfected with the pcDNA3 vector alone yielded 1,000 colonies (positive control). For all clonogenic assays, cells were cultured for 15 days in Complete Growth Media (CGM) plus G418. Surviving colonies were stained with a $0.5 \%$ crystal violet $/ 20 \%$ methanol solution and counted. ${ }^{*}=$ significantly different from HC11 cells transfected with the full length (FL) C/EBP $\delta$ expression vector at $p<0.05$.

promoter hypermethylation in acute myeloid leukemia (AML) patient samples and C/EBP $\delta$ is significantly reduced in minimally differentiated, poor prognosis, AML:M0 patient samples [11,41]. Taken together, these results indicate that $\mathrm{C} / \mathrm{EBP} \delta$ "loss of function" alterations are associated with a wide range of "solid" tumors and in leukemia.

In this report we show that reducing $\mathrm{C} / \mathrm{EBP} \delta$ expression by siRNA and gene knockout increased cell migration and invasion, consistent with a role for "loss of function" alterations in C/EBP $\delta$ in advanced cancer progression and metastasis. Importantly, these experiments demonstrate that reducing $\mathrm{C} / \mathrm{EBP} \delta$ expression levels increased cell migration under growth arrest conditions, a condition in which $\mathrm{C} / \mathrm{EBP} \delta$ expression is elevated and cell migration is dramatically inhibited (Figure 2B). These findings extend basic studies in which Slow border cells (slbo), a Drosophila basic region/leucine zipper (C/EBP) homologue, was shown to function as a regulator of border cell cluster formation, adhesion and migration in the Drosophila ovary [35]. Border cell cluster formation is a complex biological phenomenon that requires activation of adhesion and migration programs. Using "ChIP-chip" assays we previously identified C/ EBP $\delta$ target genes that function in cell adhesion, including glycoprotein $\mathrm{V}$ (GP5), protocadherin 9 (PCDH9) and integrin $\beta 8$ (ITGB8) [33]. The present results indicate that reducing $\mathrm{C} / \mathrm{EBP} \delta$ expression plays a potentially important role in promoting cell migration, a critical pathogenic event in metastasis.

C/EBP $\delta$ domain deletion experiments demonstrated that the transcriptional activator function of C/EBP $\delta$ is required for the suppression of $\mathrm{HC} 11$ cell colony growth. Colony growth suppression could result from $\mathrm{C} / \mathrm{EBP} \delta$ induced growth arrest or increased apoptosis [6]. We previously identified C/EBP $\delta$ target genes with functional roles in cell cycle regulation and apoptosis including septin 7 (SEPT7), regulator of chromosome condensation I (RCCI), DIRAS family GTP-binding Raslike 3 (DIRAS3) and BCL1-like 1 (BCL2L1) [33]. Transcriptional activation of these $\mathrm{C} / \mathrm{EBP} \delta$ target genes, or indirect activation of $\mathrm{C} / \mathrm{EBP} \delta$ associated gene networks could induce colony growth inhibition [42]. Current studies are investigating the regulation and function of selected C/EBP $\delta$ target genes in the control of cell growth, differentiation and migration/invasion.

\section{Conclusion}

An important goal in basic cancer research is to identify biological alterations that promote tumor development and progression and to use this information to design interventions strategies to prevent or treat cancer. The results of this study provide new insights into the function of C/EBP $\delta$ in cell biology using a nontransformed mammary epithelial cell line and primary embryo fibroblasts. The results provide new insights into the role of 
$\mathrm{C} / \mathrm{EBP} \delta$ as a transcriptional activator in growth control, differentiation and migration. These findings suggest that intervention strategies that increase the expression, activation or function of $\mathrm{C} / \mathrm{EBP} \delta$ could have a positive impact or reducing the incidence or impeding the progression of cancer.

\section{Methods}

\section{Cell culture}

The nontransformed HC11 mouse mammary epithelial cell line used in these studies was obtained as a generous gift from Dr. Wolfgang Doppler (University of Innsbruck). HC11 cells were cultured in complete growth media (CGM) containing RPMI 1640 medium supplemented with $5 \%$ fetal bovine serum (FBS), $10 \mu \mathrm{g} /$ $\mathrm{ml}$ bovine insulin, $10 \mathrm{ng} / \mathrm{ml}$ epidermal growth factor, $100 \mathrm{U} / \mathrm{ml}$ penicillin, $100 \mu \mathrm{g} / \mathrm{ml}$ streptomycin and 500 $\mathrm{ng} / \mathrm{ml}$ Fungizone. To induce growth arrest by serum and growth factor withdrawal, $\mathrm{HC11}$ cells were cultured to $\sim 80 \%$ confluence in CGM and then witched to media deficient in serum and growth factors (growth arrest medium, GAM, 0.1\% FBS). To induce growth arrest by contact inhibition, cells were grown to $\sim 80 \%$ confluence and maintained in CGM for up to $72 \mathrm{hrs}$.

Mouse embryo fibroblasts (MEFs) were prepared by harvesting 13.5 day old littermate embryos derived from mating of C/EBP $\delta+/$ - heterozygous mice of the C57BL/ 6 inbred strain. After removing the internal organs and forelimbs, embryos were minced with sterile scissors and incubated with $1 \mathrm{ml}$ of $0.25 \%(\mathrm{w} / \mathrm{v})$ Trypsin/EDTA solution at $4^{\circ} \mathrm{C}$ for 6 hours. After incubation, the fibroblast enriched cell preparations were rinsed and cultured in MEF complete growth media (MCGM) composed of DMEM supplemented with $10 \%(\mathrm{v} / \mathrm{v})$ FBS, $0.2 \%(\mathrm{v} / \mathrm{v})$ $0.1 \mathrm{M}$ 2-Mercaptoethanol, 1\% (w/v) L-Glutamine and $1 \%(\mathrm{w} / \mathrm{v})$ Penicillin/Streptomycin. MEFS were cultured in MCGM until crisis. Post-crises MEF colonies were isolated and cell lines were established and genotyped as C/EBP $\delta+/+$ or $-/-$. For growth arrest experiments, MEFS were cultured in media composed of DMEM plus $0.5 \%$ FBS plus antibiotics. To induce growth arrest by contact inhibition, MEFs were grown to $\sim 80 \%$ confluence and maintained in MCGM for up to $72 \mathrm{hrs}$. All cultured cells tested negative for the presence of mycoplasma using the Lonza MycoAlert Mycoplasma Detection Kit Cat\#: LT07-118 and MycoAlert Assay Control set Cat \#: LT07-518.

\section{C/EBP $\delta$ siRNA interference}

C/EBPS RNA interference was induced with short interfering RNA (siRNA) directed against the mouse single exon C/EBP $\delta$ gene as previously described [43]. C/EBP $\delta$ specific complementary 65 mer oligonucleotides with 5 'overhangs were annealed and ligated into pSilencer
2.1-U6 neo SiRNA expression vectors (Applied Biosystems/Ambion). "Scrambled" siRNAs were purchased from Dharmacon (Thermo Scientific). Scrambled siRNAs are nontargeting siRNAs based on genome Blast and microarray analysis performed by Dharmacon. Sequence verified siRNA constructs were transfected into HC11 cells using Lipofectamine (Invitrogen). Stable HC11 cell transfectants were selected by culturing in the presence of with $400 \mu \mathrm{g} / \mathrm{ml} \mathrm{G} 418$ for $\sim 15$ days. Following selection, stable $\mathrm{HC} 11$ cells were maintained in $200 \mu \mathrm{g} / \mathrm{ml} \mathrm{G418.} \mathrm{C/EBP \delta}$ expression levels were assayed by Northern and Western blots. HC11 cells with reduced $\mathrm{C} / \mathrm{EBP} \delta$ expression $(>80 \%)$ were used for further study.

\section{Northern blot analysis}

Total cellular RNA was isolated from cultured cells using RNA-Bee (Tel-Test, Inc.). Cells were rinsed with PBS and $3.5 \mathrm{ml}$ RNA-Bee was used per $100 \mathrm{~mm}$ plate. RNA was precipitated with isopropanol, washed with ice cold 75\% ethanol and the RNA pellet dissolved in DEPC water. Total RNA $(20 \mu \mathrm{g})$ was loaded onto a $1.2 \%$ agarose gel and electrophoresed for $2 \mathrm{hr}$ at $150 \mathrm{~V}$. RNA was transferred to Duralon UV membrane (Stratagene), UV cross linked, pre-hybridized and probed with $\left[\alpha-{ }^{32} \mathrm{P}\right]$ $\mathrm{dCTP}$ random primer labeled $\mathrm{C} / \mathrm{EBP} \delta, \beta$-casein and cyclophilin (CP) cDNAs probes. Hybridization was performed overnight at $42^{\circ} \mathrm{C}$. CP was used as a loading control. Results were analyzed from densitometric measurements taken by AlphaImager 2000 (Alpha Innotech). Results are representative of 3 independent experiments.

\section{Western blot analysis}

Western blots were performed as previously described [44]. Cells were rinsed with ice cold PBS, scraped from the plastic plate with a rubber policeman, and lysed in protease containing buffer for $30 \mathrm{mins}$ at $4^{\circ} \mathrm{C}$. Total cell lysates were isolated by centrifugation and the soluble supernatant was collected and protein levels quantified by BCA microprotein assay kit (Pierce). Protein lysates $(40 \mu \mathrm{g})$ were resolved by sodium dodecyl sulfate-polyacrylamide gel electrophoresis (SDS-PAGE), transferred to Immobilon-P PVDF membrane (Millipore), and membranes were blocked for $1 \mathrm{hr}$ with PBS containing $10 \%$ non-fat dry milk and 0.5\% Tween 20. Membranes were incubated with PBST containing 5\% non-fat dry milk and primary antibodies against C/EBP $\delta$ (1:1000, rabbit, Santa Cruz), cyclin D1 (1:2500, mouse, Cell Signaling), pSTAT3 (Tyr705) (1:2500, rabbit, Cell Signaling), STAT3 (1:3000, rabbit, Cell Signaling) or $\beta$-actin (1:2000, rabbit, Cell Signaling). After washing with PBS, membranes were probed with horseradish peroxidase (HRP)-conjugated anti-rabbit or anti-mouse secondary antibody (1:3000, Cell Signaling) for $1 \mathrm{hr}$. Membranes 
were developed using ECL (Pierce) and ECL plus chemiluminescence detection reagent (Amersham Pharmacia). Results are representative of 3 independent experiments.

\section{$\left[{ }^{3} \mathrm{H}\right]$-thymidine incorporation assay}

The $\left[{ }^{3} \mathrm{H}\right]$-thymidine incorporation assay was performed as previously described [8]. HC11 cells were seeded in 12 -well plates at $9 \times 10^{4} \mathrm{cell} / \mathrm{ml}$ in $1 \mathrm{ml} \mathrm{CGM}$ and grown to confluence. At the designated time points $(0$ $\mathrm{h}, 24 \mathrm{~h}, 48 \mathrm{~h}$ and $72 \mathrm{~h}), 1 \mu \mathrm{Ci} / \mathrm{ml}$ [methyl ${ }^{3} \mathrm{H}$ ]-thymidine cells was added to the culture media for $2 \mathrm{hr}$. Cell culture dishes were rinsed twice with PBS, precipitated with ice cold $10 \%$ trichloroacetic acid (TCA) for $10 \mathrm{~min}$ at $4^{\circ} \mathrm{C}$, and solubilized in $0.3 \mathrm{~N} \mathrm{NaOH}$ containing $1 \%$ SDS. Incorporation of [methyl- $\left.{ }^{3} \mathrm{H}\right]$-thymidine into TCA precipitated DNA was measured by liquid scintillation counting. Results represent the average of 2 independent experiments with 3 wells/time point.

\section{Bromodeoxyuridine (BrdU) In Situ assay}

Cells were plated on 2-well chamber slides at $\sim 9 \times 10^{4} /$ $\mathrm{ml}$, grown to near-confluence in CGM and maintained in CGM or GAM. The BrdU incorporation assay was performed using BrdU In Situ detection kit (BD Pharmingen). Briefly, 5-bromo-2-deoxyuridine was added to cells with a final concentration of $10 \mu \mathrm{M} / \mathrm{L}$ at the indicated time points and incubated for 2 hrs. Cells were fixed with ice cold methanol at $-20^{\circ} \mathrm{C}$ for $20 \mathrm{~min}$ and endogenous peroxidase activity was blocked by incubating slides in $0.3 \% \mathrm{H}_{2} \mathrm{O}_{2}$ for $10 \mathrm{~min}$. After heat antigen retrieval, slides were immunostained with biotinylated anti-BrdU antibody and detected by streptavidin-HRP and 3,3'-diaminobenzidine tetrahydrochloride (DAB). Cells were counterstained with hematoxylin for 40 seconds (Vector Lab), cleared with xylene and coverslipped.

\section{Migration "scratch" assay}

HC11 cell migration was assessed by the in vitro "scratch" assay as previously described [34,43]. Cells were plated on $100 \mathrm{~mm}$ tissue culture plates and grown to confluence. An open area or "scratch" was produced in the HC11 cell monolayer using a $200 \mu \mathrm{l}$ micropipette tip. HC11 Cells were washed with PBS to remove the displaced cells in the open area, and cultured in CGM or GAM for designated times. MEFs were similarly treated and cultured in MCGM. Migration into the open area was assessed by staining parallel dishes with $0.5 \%$ crystal violet in $20 \%$ methanol for 3 minutes.

\section{Cell invasion Assay}

Cell invasion assays were performed using the Chemicon Cell Invasion Assay Kit (Chemicon Int.). $1 \times 10^{6}$ cells were suspended in serum-free media and cultured on the inner (top) chamber of the insert; media with serum was placed in the outer (lower) chamber of the insert. Plates were incubated for up to 6 days at $37^{\circ} \mathrm{C}$. Invasive cells which had migrated to the lower surface of the membrane were stained with crystal violet and photographed. Results presented are representative of 3 independent experiments with duplicates.

\section{HC11 cell differentiation Assay}

HC11 cell differentiation assay was performed as previously described [17]. HC11 cells were seeded on 100 $\mathrm{mm}$ culture plates and grown to confluence. Confluent cells were washed with PBS twice and maintained in epidermal growth factor (EGF) free RPMI 1640 medium supplemented with $2 \% \mathrm{FBS}, 5 \mu \mathrm{g} / \mathrm{ml}$ insulin, $100 \mathrm{U} / \mathrm{ml}$ penicillin, $100 \mu \mathrm{g} / \mathrm{ml}$ streptomycin, and $500 \mathrm{ng} / \mathrm{ml}$ fungizone for two days. To induce differentiation $5 \mu \mathrm{g} / \mathrm{ml}$ prolactin (Sigma) and $0.1 \mu \mathrm{M}$ dexamethasone (Sigma) were added to the medium and cells were cultured for an additional four days. HC11 cells not treated with prolactin and dexamethasone were used as control. RNA and protein samples were isolated as described above.

\section{Clonogenic Assay}

The clonogenic assay was performed as previously described [8]. HC11 cells were transfected with $1 \mu \mathrm{g}$ of the following constructs cloned into the pcDNA3 expression vector: $\mathrm{C} / \mathrm{EBP} \delta \mathrm{cDNA}$ full length (FL), C/ EBP $\delta$ bZIP domain deleted (DB) or C/EBP $\delta$ bZIP + DNA binding domain deleted (TA) constructs. Transfections were performed using Lipofectamine Plus (Invitrogen) and following transfections cells were cultured in complete growth media plus $400 \mu \mathrm{g} / \mathrm{mL}$ G418 (Geneticin). Colonies were stained with a $0.5 \%$ crystal violet/ $20 \%$ methanol solution.

\section{Statistical Analysis}

Statistical analysis was performed using Graphpad Prism statistical software. Statistical analysis of treatment group means at multiple time points was performed by one-way analysis of variance (ANOVA). Posttest multiple comparisons of groups means was performed using Tukey's test.

\section{Abbreviations}

C/EBPS: CCAAT/Enhancer Binding Protein $\delta$; ChIP: Chromatin

Immunoprecipitation; MECs: mammary epithelial cells; MEFs: mouse embryo fibroblasts; CREB: cyclic AMP response element binding protein; Rb: Retinoblastoma protein; CDK: Cyclin dependent kinase; SAGE: Serial Analysis of Gene Expression; CML: chronic myelogenous leukaemia; BRCA1: Breast Cancer 1; VHL: Von Hippel Lindau; BrdU: Bromo deoxyUridine; STAT3:

Signaling and Activator of Transcription3; ECM: Extracellular matrix

\section{Acknowledgements}

This work was supported by National Institutes of Health grants CA57607 (JD) and P30 CA16058. 


\section{Authors' contributions}

All authors contributed to the experimental design, data interpretation, and manuscript development. $X Y, J S$ and $Y Z$ carried out the experiments, initial data analysis and figure design and optimization. JD advised on all experimental design aspects, data interpretation and final manuscript form.

\section{Competing interests}

The authors declare that they have no competing interests.

Received: 11 March 2010 Accepted: 9 December 2010

Published: 9 December 2010

\section{References}

1. Ramji DP, Foka P: CCAAT/enhancer-binding proteins: structure, function and regulation. Biochem J 2002, 365(Pt 3):561-575.

2. Johnson PF: Molecular stop signs: regulation of cell-cycle arrest by C/EBP transcription factors. J Cell Sci 2005, 118(Pt 12):2545-2555.

3. Vinson C, Myakishev M, Acharya A, Mir AA, Moll JR, Bonovich M: Classification of human B-ZIP proteins based on dimerization properties. Mol Cell Biol 2002, 22(18):6321-6335.

4. Nerlov C: The C/EBP family of transcription factors: a paradigm for interaction between gene expression and proliferation control. Trends Cell Biol 2007, 17(7):318-324.

5. O'Rourke J, Yuan R, DeWille J: CCAAT/enhancer-binding protein-delta (C/ EBP-delta) is induced in growth-arrested mouse mammary epithelial cells. J Biol Chem 1997, 272(10):6291-6296.

6. O'Rourke JP, Newbound GC, Hutt JA, DeWille J: CCAAT/enhancer-binding protein delta regulates mammary epithelial cell G0 growth arrest and apoptosis. J Biol Chem 1999, 274(23):16582-16589.

7. O'Rourke JP, Hutt JA, DeWille J: Transcriptional regulation of C/EBPdelta in $\mathrm{G}(0)$ growth-arrested mouse mammary epithelial cells. Biochem Biophys Res Commun 1999, 262(3):696-701.

8. Sivko GS, DeWille JW: CCAAT/Enhancer binding protein delta (c/EBPdelta) regulation and expression in human mammary epithelial cells: I. "Loss of function" alterations in the c/EBPdelta growth inhibitory pathway in breast cancer cell lines. J Cell Biochem 2004, 93(4):830-843.

9. Sanford DC, DeWille JW: C/EBPdelta is a downstream mediator of IL-6 induced growth inhibition of prostate cancer cells. Prostate 2005, 63(2):143-154.

10. Gery S, Tanosaki S, Hofmann WK, Koppel A, Koeffler HP: C/EBPdelta expression in a BCR-ABL-positive cell line induces growth arrest and myeloid differentiation. Oncogene 2005, 24(9):1589-1597.

11. Agrawal S, Hofmann WK, Tidow N, Ehrich M, van den Boom D, Koschmieder S, Berdel WE, Serve H, Muller-Tidow C: The C/EBPdelta tumor suppressor is silenced by hypermethylation in acute myeloid leukemia. Blood 2007, 109(9):3895-3905.

12. Gigliotti AP, Johnson PF, Sterneck E, DeWille JW: Nulliparous CCAAT/ enhancer binding proteindelta (C/EBPdelta) knockout mice exhibit mammary gland ductal hyperlasia. Exp Biol Med (Maywood) 2003, 228(3):278-285.

13. Tang D, Sivko GS, Dewille JW: Promoter methylation reduces C/EBPdelta (CEBPD) gene expression in the SUM-52PE human breast cancer cell line and in primary breast tumors. Breast Cancer Res Treat 2005, 1-10.

14. Porter D, Lahti-Domenici J, Keshaviah A, Bae YK, Argani P, Marks J, Richardson A, Cooper A, Strausberg R, Riggins GJ, et al: Molecular markers in ductal carcinoma in situ of the breast. MolCancer Res 2003, 1(5):362-375.

15. Porter DA, Krop IE, Nasser S, Sgroi D, Kaelin CM, Marks JR, Riggins G, Polyak K: A SAGE (serial analysis of gene expression) view of breast tumor progression. Cancer Res 2001, 61(15):5697-5702.

16. Kuramoto T, Morimura K, Yamashita S, Okochi E, Watanabe N, Ohta T, Ohki M, Fukushima S, Sugimura T, Ushijima T: Etiology-specific gene expression profiles in rat mammary carcinomas. Cancer Res 2002, 62(13):3592-3597.

17. Dearth $L R$, Hutt J, Sattler A, Gigliotti A, DeWille J: Expression and function of CCAAT/enhancer binding proteinbeta (C/EBPbeta) LAP and LIP isoforms in mouse mammary gland, tumors and cultured mammary epithelial cells. J Cell Biochem 2001, 82(3):357-370.

18. Strathdee G, Brown R: Aberrant DNA methylation in cancer: potential clinical interventions. Expert Rev Mol Med 2002, 4(4):1-17.
19. Borrelli S, Testoni B, Callari M, Alotto D, Castagnoli C, Romano RA, Sinha S, Vigano AM, Mantovani R: Reciprocal regulation of p63 by C/EBP delta in human keratinocytes. BMC Mol Biol 2007, 8:85.

20. Lane MD, Tang QQ, Jiang MS: Role of the CCAAT enhancer binding proteins (C/EBPs) in adipocyte differentiation. BiochemBiophysResCommun 1999, 266(3):677-683.

21. Takeda K, Noguchi K, Shi W, Tanaka T, Matsumoto M, Yoshida N, Kishimoto T, Akira S: Targeted disruption of the mouse Stat3 gene leads to early embryonic lethality. Proc Natl Acad Sci USA 1997, 94(8):3801-3804.

22. Wang ND, Finegold MJ, Bradley A, Ou CN, Abdelsayed SV, Wilde MD, Taylor LR, Wilson DR, Darlington GJ: Impaired energy homeostasis in C/ EBP alpha knockout mice. Science 1995, 269(5227):1108-1112.

23. Ishii Y, Kasukabe T, Honma Y: Induction of CCAAT/enhancer binding protein-delta by cytokinins, but not by retinoic acid, during granulocytic differentiation of human myeloid leukaemia cells. Br J Haematol 2005, 128(4):540-547.

24. Hanahan D, Weinberg RA: The hallmarks of cancer. Cell 2000, 100(1):57-70.

25. Hutt JA, O'Rourke JP, DeWille J: Signal transducer and activator of transcription 3 activates CCAAT enhancer-binding protein delta gene transcription in G0 growth-arrested mouse mammary epithelial cells and in involuting mouse mammary gland. I Biol Chem 2000, 275(37):29123-29131.

26. Cantwell CA, Sterneck E, Johnson PF: Interleukin-6-specific activation of the C/EBPdelta gene in hepatocytes is mediated by Stat3 and Sp1. Mol Cell Biol 1998, 18(4):2108-2117.

27. Sivko GS, Sanford DC, Dearth LD, Tang D, DeWille JW: CCAAT/Enhancer binding protein delta (c/EBPdelta) regulation and expression in human mammary epithelial cells: II. Analysis of activating signal transduction pathways, transcriptional, post-transcriptional, and post-translational control. J Cell Biochem 2004, 93(4):844-856.

28. Grant SL, Douglas AM, Goss GA, Begley CG: Oncostatin M and leukemia inhibitory factor regulate the growth of normal human breast epithelial cells. Growth Factors 2001, 19(3):153-162.

29. Hutt JA, DeWille JW: Oncostatin M induces growth arrest of mammary epithelium via a CCAAT/enhancer-binding protein delta-dependent pathway. Mol Cancer Ther 2002, 1(8):601-610.

30. Vultur A, Cao J, Arulanandam R, Turkson J, Jove R, Greer P, Craig A, Elliott B, Raptis L: Cell-to-cell adhesion modulates Stat3 activity in normal and breast carcinoma cells. Oncogene 2004, 23(15):2600-2616.

31. Minami M, Inoue M, Wei $S$, Takeda $K$, Matsumoto M, Kishimoto T, Akira S: STAT3 activation is a critical step in gp130-mediated terminal differentiation and growth arrest of a myeloid cell line. Proc Natl Acad Sci USA 1996, 93(9):3963-3966.

32. Spiotto MT, Chung TD: STAT3 mediates IL-6-induced growth inhibition in the human prostate cancer cell line LNCaP. Prostate 2000, 42(2):88-98.

33. Zhang Y, Liu T, Yan P, Huang T, Dewille J: Identification and characterization of CCAAT/Enhancer Binding proteindelta (C/EBPdelta) target genes in G0 growth arrested mammary epithelial cells. BMC Mol Biol 2008, 9(1):83.

34. Liang CC, Park AY, Guan JL: In vitro scratch assay: a convenient and inexpensive method for analysis of cell migration in vitro. Nat Protoc 2007, 2(2):329-333.

35. Jang AC, Starz-Gaiano M, Montell DJ: Modeling migration and metastasis in Drosophila. J Mammary Gland Biol Neoplasia 2007, 12(2-3):103-114.

36. Simpson KJ, Selfors LM, Bui J, Reynolds A, Leake D, Khvorova A, Brugge JS: Identification of genes that regulate epithelial cell migration using an siRNA screening approach. Nat Cell Biol 2008, 10(9):1027-1038.

37. Cao Z, Umek RM, MCKnight SL: Regulated expression of three C/EBP isoforms during adipose conversion of 3T3-L1 cells. Genes Dev 1991, 5(9):1538-1552.

38. vom Brocke J, Schmeiser HH, Reinbold M, Hollstein M: MEF immortalization to investigate the ins and outs of mutagenesis. Carcinogenesis 2006, 27(11):2141-2147.

39. Ikezoe T, Gery S, Yin D, O'Kelly J, Binderup L, Lemp N, Taguchi H, Koeffler HP: CCAAT/enhancer-binding protein delta: a molecular target of 1,25-dihydroxyvitamin D3 in androgen-responsive prostate cancer LNCaP cells. Cancer Res 2005, 65(11):4762-4768.

40. Ray A, Ray BK: Serum amyloid A gene expression under acute-phase conditions involves participation of inducible C/EBP-beta and C/EBPdelta and their activation by phosphorylation. Mo/Cell Biol 1994, 14(6):4324-4332. 
41. Silva FP, Swagemakers SM, Erpelinck-Verschueren C, Wouters BJ, Delwel R, Vrieling H, van der Spek P, Valk PJ, Giphart-Gassler M: Gene expression profiling of minimally differentiated acute myeloid leukemia: $\mathrm{MO}$ is a distinct entity subdivided by RUNX1 mutation status. Blood 2009, 114(14):3001-3007.

42. Litvak V, Ramsey SA, Rust AG, Zak DE, Kennedy KA, Lampano AE, Nykter M, Shmulevich I, Aderem A: Function of C/EBPdelta in a regulatory circuit that discriminates between transient and persistent TLR4-induced signals. Nat Immunol 2009, 10(4):437-443.

43. Zhou S, Si J, Liu T, DeWille JW: PIASy represses CCAAT/enhancer-binding protein delta (C/EBPdelta) transcriptional activity by sequestering $\mathrm{C} /$ EBPdelta to the nuclear periphery. J Biol Chem 2008, 283(29):20137-20148.

44. Zhou S, Dewille JW: Proteasome-mediated CCAAT/enhancer-binding protein delta (C/EBPdelta) degradation is ubiquitin-independent. Biochem J 2007, 405(2):341-349.

doi:10.1186/1475-2867-10-48

Cite this article as: Yu et al:: CCAAT/Enhancer Binding Protein-delta (C/ EBP-delta) regulates cell growth, migration and differentiation. Cancer Cell International 2010 10:48.

\section{Submit your next manuscript to BioMed Central} and take full advantage of:

- Convenient online submission

- Thorough peer review

- No space constraints or color figure charges

- Immediate publication on acceptance

- Inclusion in PubMed, CAS, Scopus and Google Scholar

- Research which is freely available for redistribution

Submit your manuscript at www.biomedcentral.com/submit
C Biomed Central 